\title{
Fracture Load of Tooth Restored with Fiber Post and Experimental Short Fiber Composite
}

\author{
Jasmina Bijelic ${ }^{1, *}$, Sufyan Garoushi ${ }^{1}$, Pekka K. Vallittu ${ }^{2}$ and Lippo V.J. Lassila ${ }^{1}$ \\ ${ }^{I}$ Turku Clinical Biomaterials Centre, Institute of Dentistry, University of Turku, Turku, Finland \\ ${ }^{2}$ Department of Biomaterials Science, Institute of Dentistry and BioCity Turku Biomaterials Research Program, Univer- \\ sity of Turku, Turku, Finland
}

\begin{abstract}
:
Purpose: This study evaluated the load bearing capacity of anatomically designed canines restored with FRC posts and experimental short fiber composite resin (FC). The effect of using three different types of tooth preparation and woven net on the fracture load was also investigated. Further aim was to evaluate the failure mode of each restoration.

Material and methods: 80 maxillary frasaco-canines were divided into 10 groups $(n=8)$. The anatomic crowns were cut perpendicular at CEJ of the tooth. Group 1 was composed of teeth with flattened surface. Groups 2, 3 \& 4 were prepared of teeth with $2 \mathrm{~mm}$ ferrule. In the third group, everStick Net was applied above the ferrule. Group 5 was composed of teeth with large box type preparation. The root canals were enlarged, sandblasted and then surface treated with Stick resin for $5 \mathrm{~min}$. Two types of FRC root canal posts were used. The crowns were prepared either with composite resin or with FC. A static load until failure was applied to the crowns at a 45 degrees angle. Failure modes were visually examined.

Results: ANOVA revealed that use of FRC-post and tooth preparation $(\mathrm{p}<0.001)$ had significant effect on fracture load of FRC-crown. The crowns made from only FC gave comparable fracture load to groups with FRC-post. No significant difference was found in load-bearing capacity between restorations reinforced with FRC net-substructure and those without ( $>>0.001)$. Chi-square test revealed that both, crown design and existence of FRC-post effected significantly fracture types $(\mathrm{p}<0.001)$.

Conclusion: FC demonstrated similar load bearing capacity with restorations reinforced with FRC post. The presence of ferrule around the tooth increased the load bearing capacity significantly.

Abbreviations: EET - endodontically treated teeth; FRC - fiber-reinforced composite; semi-IPN - semi-interpenetrating network; CEJ - cementoenamel junction; FC - experimental short fiber composite; $\mathrm{SiC}$ - silicon carbide abrasive paper; $\mathrm{N}$ - newton; FEM - finite element method.
\end{abstract}

Key Words: Individually formed fiber-post, Experimental fiber-reinforced composite, Fracture load.

\section{INTRODUCTION}

Modern dentistry aims at preserving pulpal vitality and post application is considered as last therapeutic option when restoring a damaged crown [1]. It is assumed that the endodontically treated teeth (ETT) are weaker and more prone to fracture because of desiccation or premature loss of moisture supplied by a vital pulp [2]. The generally accepted explanation for the increased failure rate is the substantially decreased structural integrity of the tooth because of the removal of the tooth structure during endodontic access, dowel-space preparation and cavity preparation [3]. The challenge may be complicated by substantial loss of coronal tooth structure and the ability to predict restorative success [4]. Due to substantial loss of coronal tooth structure, corono-radicular stabilization is often required, especially in anterior teeth to provide retention and resistance form for the restoration [5]. A post is usually claimed to be placed in or-

*Address correspondence to this author at the Turku Clinical Biomaterials Centre - TCBC, Itäinen Pitkäkatu 4 B, FI-20520 Turku, Finland; Tel: +358 2333 8203; Fax: +358 2333 8390; E-mail: jasmina.bijelic@utu.fi der to strengthen the tooth, maximize the retention of the construction and minimize the fracture risk of the root. However, many in vitro and in vivo studies have showed that a post does not reinforce ETT, but serve as a support for the core foundation when there is insufficient clinical crown remaining [4-6].

Fiber-reinforced composite (FRC) posts have been suggested as a group of materials which offers stiffness equal to that of dentin, as well as high durability and therefore have some advantages over metal posts $[7,8]$. It is also noted that the rigidity of the post should be equal or close to that of the root of the tooth in order to distribute the occlusal forces along the length of the root [9]. In this aspect, the modulus of elasticity of a FRC post is closer to that of dentin when compared with rigid metal posts [7] and FRC endodontic posts exhibit the flexural strengths which generally exceed the yield strength of metals [10]. The flexural moduli but not the flexural strengths of FRC posts appear to correlate with fiber type [10]. FRC posts are reported also to reduce the risk of tooth fractures and display higher survival rates than teeth restored with rigid zirconia post [11]. In addition, the restoration of endodontically treated teeth with metal-free materi- 
als eliminates the hazards of corrosion and allergic hypersensitivity and even more, the FRC post also have the advantage of easy removal if endodontic retreatment is required. FRCs can be used in root canal as prefabricated posts and individually formed posts [12]. A prefabricated FRC root canal post consists of reinforcing fibers and fully polymerised resin matrix between the fibers having predetermined diameter $[7,12]$. The problem with the material is that the polymer matrix between the fibers is highly cross-linked and due to the high degree of conversion is non-reactive. This makes it difficult to bond the prefabricated FRC posts to composite resin cement and tooth structure [13]. On the other hand, individually formed posts with semi-interpenetrating polymer network (semi-IPN) showed good bonding [7]. In the semi-IPN structure, there are both linear polymer phases and cross-linked polymer phases mixed at the level of polymer chains [14]. The monomers of the adhesive resin and cements can diffuse into the linear polymer phase and by polymerization form an interdiffusion bonding, called a secondary-IPN bonding [15].

Retention and resistance to fracture are two important factors that must be achieved with post- and core retained restoration. When using posts, factors such as the length, design, diameter, surface treatment and material of the post as well as canal shape, luting medium and method of cementation should be considered as factors affecting the retention of the post system [16-18]. Resistance to fracture on other hand is related to the thickness of remaining dentin [18]. However, it is suggested that a ferrule design can also significantly improve the fracture resistance of ETT [4, 19]. Incorporation of ferrule has been said to be a key element of tooth preparation when using a post and core $[3,20]$. The majority of studies regarding the effectiveness of a ferrule support the need of $1.5-2 \mathrm{~mm}$ of ferrule height. The $2 \mathrm{~mm}$ of tooth of coronal structure above the cementoenamel junction (CEJ) is superior to the lack of a ferrule in the prevention of tooth fracture under a static load, but also a tooth with a nonuniform ferrule is more effective than a tooth with no ferrule [3]. The ferrule effect should prevent also fracture of the root, fracture of the post and dislodgement of the post [4] and increase the fracture resistance of ETT, regardless of the dowel (post) system used [21].

Previous studies showed favorable type of failure (debonding), when FRC (woven) as substructure to composite resin core material was used [22, 23]. Furthermore, using similar material as post-core complex is suggested to be beneficial [24]. However, the relatively high brittleness and low fracture toughness of current composite resins still limit their use in large stress-bearing restorations. Studies have been undertaken to improve restorative composite resins. Although previous investigations on the use of experimental short fiber composite resin (FC) as reinforced restorative filling composite show enhancement in flexural strength and load-bearing capacity [25-27], the effect of short glass-fiber reinforcement on post-crown complex is not clear yet. It can be hypothesized that the use of individually formed FRC post and short E-glass fiber fillers can reinforce the composite resin restoration and improve the load bearing capacity of post-crown complex.

Thus, the aim of this study was to evaluate the fracture load i.e. load bearing capacity of anatomically designed canines restored with two types of individually formed FRC posts and woven net. We also investigated the effect of using three different types of tooth preparation and FC composite on the fracture load determining the fracture type for each group in addition.

\section{MATERIALS AND METHODS}

\section{Specimen Preparation}

The materials used in this study are listed in Table 1. A new experimental short fiber composite (FC) was prepared as described previously [25, 26]. Eighty anatomically designed maxillary canines (phantom frasaco canines, Ger-

Table 1. Materials Used in the Study

\begin{tabular}{|c|c|c|c|c|}
\hline Brand & Manufacturer & Lot No. & Monomer \& Fiber Content & Type of Material \\
\hline Stick Resin & $\begin{array}{l}\text { Stick Tech Ltd, Turku, } \\
\text { Finland }\end{array}$ & 5709295 & bis-GMA, TEGDMA & Unfilled light-curing resin \\
\hline everStick & $\begin{array}{l}\text { Stick Tech Ltd, Turku, } \\
\text { Finland }\end{array}$ & 2070319-ES-182 & E-glass, PMMA, bis-GMA, & $\begin{array}{c}\text { Resin-preimpregnated continuous } \\
\text { unidirectional FRC }\end{array}$ \\
\hline everStickNet & $\begin{array}{l}\text { Stick Tech Ltd, Turku, } \\
\text { Finland }\end{array}$ & 2041227-EN-073 & E-glass, PMMA, bisGMA, & $\begin{array}{l}\text { Resin-preimpregnated continuous } \\
\text { bidirectionally oriented FRC }\end{array}$ \\
\hline $\mathrm{Z} 100$ & $3 \mathrm{M}$, St Paul, MN, USA & $200611096 \mathrm{CE}$ & $\begin{array}{l}\text { bis-GMA, TEGDMA, } \\
66 \text { vol } \% \text { fillers }\end{array}$ & Hybrid resin composite \\
\hline ParaCem ${ }^{\circledR}$ Catalyst & $\begin{array}{l}\text { Coltène/Whaledent AG, } \\
\text { Altstätten, Switzerland }\end{array}$ & 0144828 & $\begin{array}{l}\text { bis-GMA, bis-EMA, TEGD- } \\
\text { MA, Barium glass silanized, } \\
\text { Amorphous silica, Benzoyl } \\
\text { peroxide }\end{array}$ & Dual-curing cement \\
\hline
\end{tabular}


many) made of hard thermosetting plastic material and of same size were divided upon collection into ten groups. Before preparation, an impression was taken using a transparent polyvinyl siloxane for direct application (Memosil 2, Heraeus Kulzer, Hanau, Germany) in order to obtain moulds for creating crown with the original form and shape of the origin frasaco canine tooth. The anatomic crowns of all teeth were then cut perpendicular to the long axis of the tooth, using a diamond disc (Giflex, Bredent, Senden, Germany) and teeth surfaces were ground using a silicon carbide $(\mathrm{SiC})$ abrasive paper 180-grit (Struers, Copenhagen, Denmark) under water cooling using a grinding machine (Struers, LaboPol-21, Struers, Copenhagen, Denmark), until root canal appeared. All teeth were assigned to ten experimental groups $(n=8)$. The root canals in all groups were first sandblasted with micro-abrasive sand of $50 \mu \mathrm{m}$ at $300 \mathrm{kPa}$ (Vaniman, Fallbrook $\mathrm{CA}$, California) and then surface treated (wetted) with resin (StickResin, Stick tech, Ltd, Turku, Finland) for 5 min. Protection from any light source was achieved by a lightproof box (3M-ESPE, Germany) until the individually FRC posts were finally inserted.

\section{Restorative Procedure}

\section{Post Fabrication}

The direct posts and crowns were fabricated according to the groups they belonged (Fig. 1). The first control group was composed of teeth with flattened surface i.e. without coronal structure (no ferrule). The second, third and fourth control groups were composed of teeth with $2 \mathrm{~mm}$ of remaining coronal structural ( $2 \mathrm{~mm}$ ferrule). The fifth control group was composed of teeth with large box type preparation (depth of $2 \mathrm{~mm}$ ) using diamond instrument with guide pin (GEBR., Brasseler, Lemgo, Germany). Due to the fact the guide pin is non diamond-coated, a controlled and defined preparation line was created with 1.5 thickness of the circumferential wall. All preparations were made under water cooling. Control groups were prepared with no fiber reinforced post included into the structure.
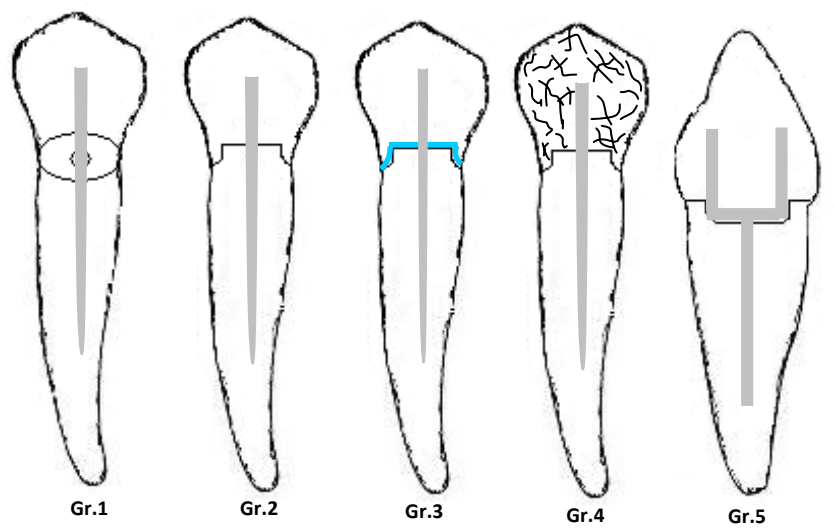

Fig. (1). Gr.1: Flattened root surface; Gr.2: $2 \mathrm{~mm}$ ferrule; Gr.3: 2 $\mathrm{mm}$ ferrule; the blue bold line represents the placement of woven net above ferrule; Gr.4: $2 \mathrm{~mm}$ ferrule; the black short lines represent the experimental fiber composite resin (FC) and Gr.5: large box like preparation. The grey figures in all schematic drawns represent the FRC-post.

The groups with individually formed FRC root canal posts with a semi-IPN polymer matrix (everStick ${ }^{\circledR}$, Stick
Tech Ltd, Turku, Finland) were prepared on same way respectively for each control group. All posts in this study contained a semi-IPN polymer matrix after light-polymerization and therefore are referred as individually formed FRC posts. The root canals were sequentially enlarged up to $1.7 \mathrm{~mm}$ and the procedure was standardized by using two different drills under water cooling. In the first, second, third and fourth group the posts were formed with the hole post space filled up with fibers from one fiber bundle of everStick with a length of $14 \mathrm{~mm}$ (equal to two thirds of the length of the crown in the coronal part of the tooth) and diameter of 1.5 $\mathrm{mm}$. First the bundle was inserted into the enlarged canal, both ends (the apical and coronal end) were fitted in leaving $4 \mathrm{~mm}$ of fiber bundle above the coronal opening and then light-polymerized (Optilux 501, Kerr, Danbury, USA) with a wavelength of the visible light (halogen) between 380 and $520 \mathrm{~nm}$ with maximal intensity at $470 \mathrm{~nm}$ and light irradiance at $800 \mathrm{~mW} / \mathrm{cm}^{2}$ in situ for $20 \mathrm{~s}$. After it was removed from the root canal, the individually formed FRC post was further light-polymerized for $40 \mathrm{~s}$ outside the canal. In the third group, everStick Net with thickness of $0,06 \mathrm{~mm}$ was additionally applied above the ferrule and light-polymerized for $20 \mathrm{~s}$. In the fifth group the posts were prepared with the fibers formed into a hollow tube from one fiber bundle of everStick with a length of $14 \mathrm{~mm}$ and diameter of $1.5 \mathrm{~mm}$. The coronal end of the fiber bundle was branched before the polymerization in the canal, each branch pressed against the palatal and buccal surfaces and then light-polymerized in situ for $20 \mathrm{~s}$, thus forming a "hollow" structure (Fig. 1). After it was removed from the root canal, the post was further lightpolymerized for $40 \mathrm{~s}$ outside the canal. The individually formed FRC root canal posts were prepared as same as possible for each specimen in each group.

\section{Cementation of the Posts}

The posts were cemented with a dual-curing composite resin luting cement (ParaCem ${ }^{\circledR}$ Universal DC, Coltène/ Whaledent, Altstätten, Switzerland) according to the manufacturer's instructions. The base and catalyst were first dispensed in ratio 1:1 and then mixed on the mixed pat for 20$30 \mathrm{~s}$ until homogeneous paste was formed. Previously sandblasted, gently air-dried and adhesively (with Stick Resin for $5 \mathrm{~min}$ ) treated surfaces of the root canals were coated with the mixed cement and individually formed FRC post were inserted into the root canal with slight finger pressure. A thin layer of cement was also placed on the post surface before the insertion into the root canal. Excess cement was removed. The coronal end of each post was positioned directly in contact with the tip of the light-curing unit and was lightpolymerized for $30 \mathrm{~s}$. The crowns were prepared as soon as the cement has hardened, approximately 4 min after cementation.

\section{Crown Fabrication}

In order to obtain crowns with the original form and shape as well as to standardize the crown dimensions, mould of transparent polyvinyl siloxane for direct application was prepared. The commercial composite resin (Z100, 3M Espe, St.Paul, USA) and experimental FC composite resin were applied into the transparent mould, which was then placed on the tooth surface with slight pressure. After the excess was removed with suitable instrument, the crown was light- po- 


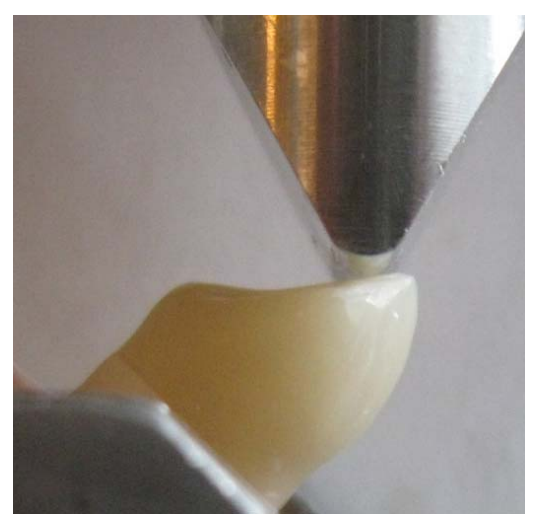

Fig. (2). Position of loading tip on the crown and the load test setup.

lymerized from two sides for $20 \mathrm{~s}$ outside the mould. Once the mould was removed, the crown was further light cured for another $40 \mathrm{~s}$ ( $20 \mathrm{~s}$ per side). All the crowns were finished and polished with diamond burrs, white stones and diamond polishing cup under water cooling.

After finishing the restorative procedure, the teeth were embedded in the middle of an acrylic resin (Palapress, Heraeus Kulzer, Wehrheim, Germany) cylinder (diameter 20 $\mathrm{mm}$, height approximately $15 \mathrm{~mm}$ ) at a level of $2 \mathrm{~mm}$ below the lowest point of the simulated CEJ, simulating the bone level.

\section{Mechanical Testing: Fracture Load Test}

The test specimens were dry stored at room temperature for 10 days before testing. A static load until failure was applied to the crowns $2 \mathrm{~mm}$ below the incisal edge on the palatal side at a 45 degrees angle, using a universal testing machine (Lloyd LRX, Lloyd Instruments Ltd, Fareham, UK) with cross head speed of $1 \mathrm{~mm} / \mathrm{min}$ (Fig. 2). The specimens were loaded until fracture with load values measured in Newtons (N). Differences regarding the mode of failure among the groups were visually analysed and divided into two groups according to the failure mode (Table 2): favorable type (restorable) above or at the simulated bone level which has easy possibility to repair and unfavorable type (nonrestorable) below the simulated bone level which is difficult to repair.

\section{Statistical Analysis}

Data of the fracture-load values were statistically analyzed with SPSS version 10 (SPSS Inc, Chicago, IL, USA) using analysis of variance (ANOVA) followed by the

Table 2. Failure Mode Distribution of Test Specimens

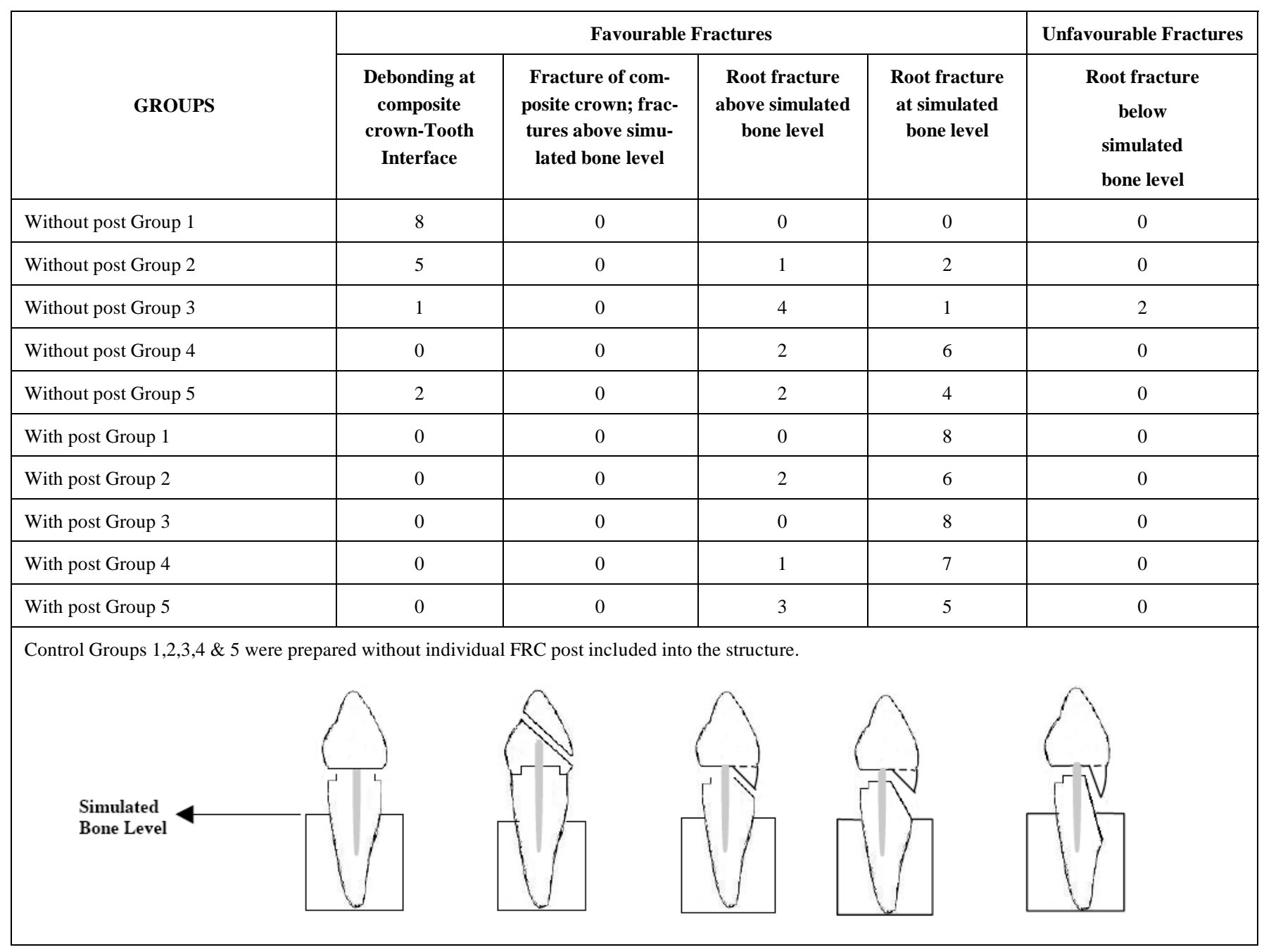


Tukey's post hoc test and fracture types were analysed with chi-square test at a significance level of 0.05 to determine the differences between the groups.

\section{RESULTS}

ANOVA revealed that use of FRC-post and tooth preparation had significant $(\mathrm{p}<0.001)$ effect on fracture load of restorations. Fig. (3) summarizes the mean fracture loads and standard deviations for the test groups. ANOVA revealed that restorations made from experimental $\mathrm{FC}$ composite resin (Group 4) gave highest fracture load values $(238 \mathrm{~N})$ when FRC-post was not included into the structure. For the rest of the groups, the data showed that crowns additionally reinforced with post have higher load-bearing capacity than crowns without post. No significant difference was found in load-bearing capacity between restorations reinforced with FRC net-substructure and those without $(p>0.001)$. Chisquare test revealed that both, crown design and existence of FRC-post effected significantly fracture types $(p<0.001)$. Restorations made from experimental FC composite resin (Group 4) revealed no statistically difference $(p>0.05)$ in fracture pattern, whether FRC-post was included into the structure or not. In all other groups, fracture pattern was significantly changed if FRC-post was added.

The $2 \mathrm{~mm}$ remaining coronal structure (ferrule) above the CEJ appeared to reinforce the cervical area, where most fractures occur. Failure mode analysis showed cervical root fractures. The results of failure mode assessment and typical fracture modes are shown in Table $\mathbf{2}$.

\section{DISCUSSION}

Since the natural teeth simulate the clinical conditions, their use for in vitro studies has been considered as acceptable $[28,29]$. However, the experimental use of natural teeth presents problems due to anatomic variations and the heterogeneous nature of tooth matter [29], and existing microcracks in the dentin may not always be seen before testing [30]. The use of natural teeth results in a large variation in test results, compared with artificially manufactured teeth [31]. Although, investigators are statistically evaluating the root length and faciolingual or mesiodistal dimensions of the teeth to minimize the confounding factors, variations in canal morphology and biochemical composition might also affect mechanical test results [32]. Moreover, natural canines are hardly available and tend to have larger variations in size. In order to avoid the conflicting results and to minimize the variations in the teeth selection, anatomically designed canines (phantom frasaco teeth) were used in the present study.

If a large amount of tooth structure has been removed as the result of endodontic therapy, the build-up with a post and core in combination with a crown becomes necessary. It has been suggested that a post should have the same modulus of elasticity as root dentin to distribute applied forces evenly along the length of the post [5].

The present study was designed to evaluate the loadbearing capacity and failure mode of maxillary canines restored with resin composite crown with or without placement of individually formed FRC root canal post and woven net. This study reproduced the scenario of major loss of tooth structure. Two types of individually formed FRC root canal post designs were used in this study: post with the hole post space filled up with fibers and post with the fibers formed into a hollow tube (Fig. 1). The presence or absence of FRC root canal post in this study resulted in a significant difference whether regarding the fracture load or failure pattern and in that aspect the hypothesis was accepted. Individually formed FRC root canal post significantly contributed to the reinforcement and strengthening of restored teeth by supporting the remaining tooth structure.

Adhesive resin cement was used to cement the posts. They have the ability to bond to both the radicular dentin and post allowing the use of conservative post insertion techniques as well as reducing potential stress [28]. Pontius et al demonstrated that much higher tensile forces were needed to dislodge prefabricated posts when bonding agents were used [5]. The root systems restored with a dentin bonding cement are more resistant to failure than root systems that use zinc phosphate as the cement medium [33]. For fiber reinforced post, resin cement is generally used [31]. The present study favors the use of dentin bonding agents in combination with composite resin.

Composite resin material was material of choice for preparation of crown in this study, because of its good bond strength, controlled and quick setting and good aesthetic. When force is applied to composite or layered materials, stresses tend to maximize within the material with the highest elastic modulus and the stress located at the dentin may influence the risk or root fracture, whereas, the stress located at post-dentin interface may influence the risk of loss of post retention [34]. Root fractures on root-filled abutment teeth are severe failures, often with fatal consequences for the involved tooth and prosthetic reconstruction [35]. When a system with components of different rigidity is loaded, the more rigid component is capable of resisting greater forces without distortion. Stress instead transferred to the less rigid component which might cause the weaker component to fail [35]. A post material with a modulus of elasticity similar to that of dentin would be less predisposed to induce root fractures. Therefore, may be suggested that using restorative materials of elastic modulus close to dentin rather than materials of high elastic modulus may create a mechanically homogenous unit.

The type of crown has been shown to not be a significant factor affecting the fracture resistance, whereas the presence/absence of post was a significant factor [36]. It has also been shown that providing coronal coverage significantly increased the stiffness of the remaining tooth and in the instance of minimal remaining tooth structure, a foundation is required to retain the crown, often with the placement of a dowel to provide retention for the foundation restoration [3]. Transmission of occlusal forces has been shown to intraradicularly predispose the root to vertical fracture [2]. Hence, the restoration design must provide enough strength to restoration and the abutment tooth to resist occlusal forces. In order to establish the effect of the preparation type of the restoration on the fracture load, the present study compared presence of $2 \mathrm{~mm}$ ferrule of sound tooth to absence of ferrule (flattened root surface) and large box type of preparation. 


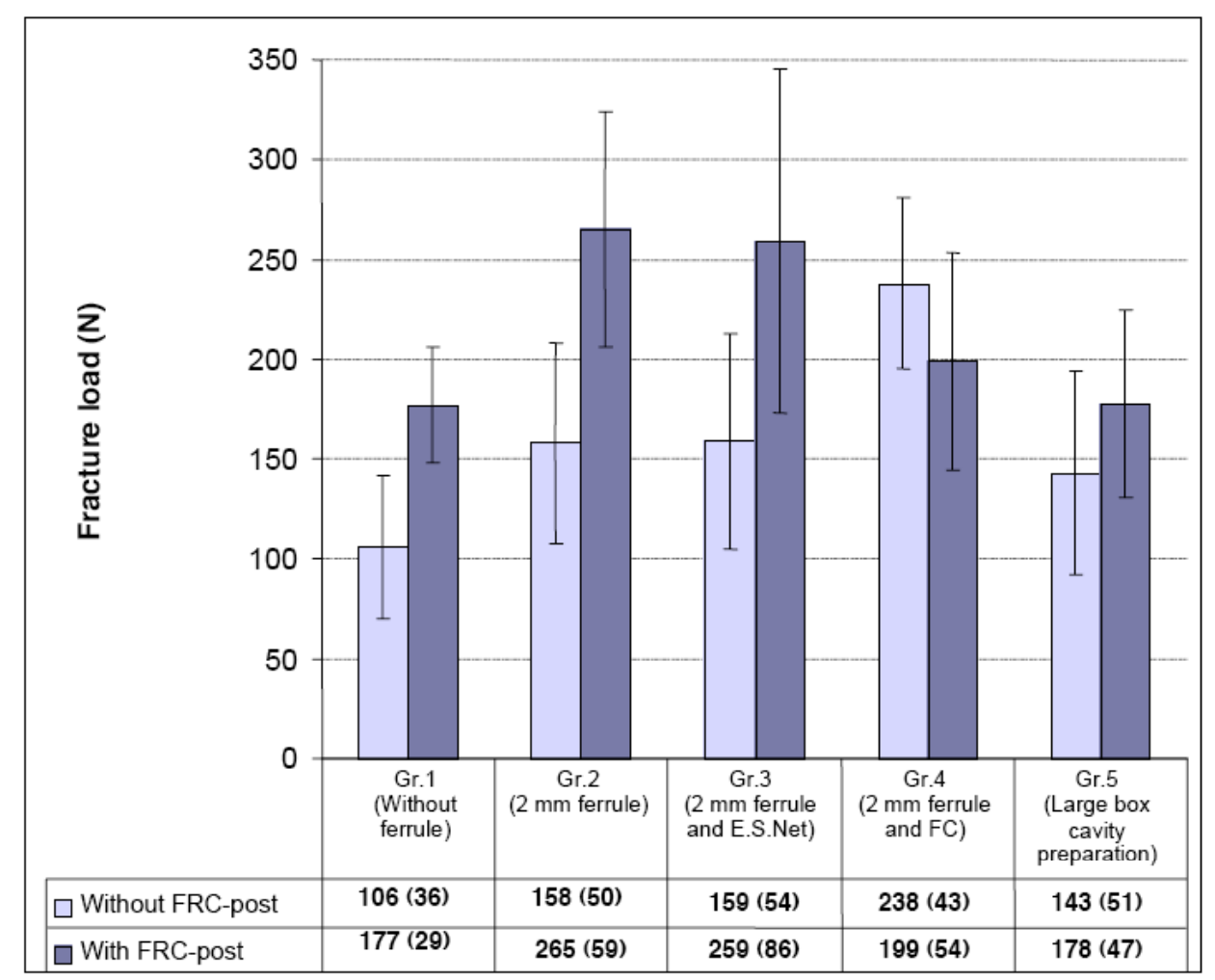

Fig. (3). Fracture load (N) and standard deviations of the tested groups.

The presence of ferrule is hypothesized to protect the tooth from wedging stresses in post-restored teeth [34] and the incorporation of ferrule is described as a key element of tooth preparation using dowel and core [3]. When the ferrule effect is present, stresses are redistributed in the outer surface regions of the coronal third of the root [36]. When the ferrule is absent, occlusal forces must be resisted exclusively by a post that may eventually fracture, otherwise vertical root fracture may occur [2]. Furthermore, occlusal forces would become concentrated at the junction of the dowel (post) and the core with potential for dowel fracture [21,36]. It has been reported that a cervical ferrule preparation creates a positive effect in terms of reducing stress concentration at the core dentin junction for crowned and ETT subject to stress in the cervical region [36] therefore being determining factor [37]. This is of great matter, because the reconstructed tooth is subject to most stress in the cervical region. The FEM study has also confirmed that the stress is concentrated at the cervical region and the ferrule preparation was effective in reducing the stress values [34]. The presence of $2 \mathrm{~mm}$ peripheral ferrule in the present study appeared to play an important role in reinforcing the cervical area, where most fractures occur.

It was hypothesized that the use of short E-glass fiber fillers can reinforce the composite restoration therefore improving the load bearing capacity of the post-crown complex. The results of the present compressive load test revealed substantial improvement in the load bearing capacity of crowns made from experimental FC composite reinforced with short E-glass fiber fillers (Group 4) in comparison with a conventionally used restorative composite with or without FRC-substructure (Groups 2 and 3). Also interestingly was that the fracture pattern with or without post corresponded with the load values, which might suggest that FC composite plays major role in load bearing capacity. In order the fiber to act as an effective reinforcement for polymers, stress transfer from the polymer matrix to the fibers is essential and is achieved by having fiber length equal to or greater than the critical fiber length [25]. Based on this knowledge, experimental FC used in this study has a fiber fillers of $3 \mathrm{~mm}$ in length. In theory, the reinforcing effect of the fiber fillers is based not only on stress transfer from the polymer matrix to the fibers, but also on the behavior of individual fibers as stress breakers. On the other hand, the use of FC composite with FRC post did not bring any improvement (Fig. 3). This is most likely due to the difference in stiffness (modulus of elasticity) between two structures.

In terms of failure mode, earlier investigations have showed that most common failure when using the direct technique (prefabricated post and composite resin) was the fracture of the restorative material (composite) and when using the indirect technique (cast post and core), the most common failure was the fracture of the root. Hence, the direct method appeared to protect the tooth structure and was recommended as appropriate method [4]. It has also been shown that the fiber dowels (posts) were able to reduce the risk of root fracture and that the fiber-reinforced dowels with composite cores achieved a fracture strength that was not significantly different from the gold alloy [21]. The majority of the specimens in the present study showed fracture at the crown-root margin on the palatal side (loading side). Fracture line continued toward the buccal root surface ending above or at the simulated bone level (favorable fracture). This is in accordance to the previous study of Le Bell et al [30]. The large box type preparation might had an effect on the results and might be concluded that whether a post struc- 
ture strengthens the restored tooth depends on the post system used and ferrule length. The difference in fracture load between the teeth with a $2 \mathrm{~mm}$ uniform ferrule, teeth with absence of ferrule and teeth with large box type of preparation is attributed to the difference in remaining coronal structure. This is in accordance with the results of Tan et al where uniform and nonuniform ferrule types were tested [3]. The extra dentin in the groups with $2 \mathrm{~mm}$ ferrule might have created a more stable foundation for the individually formed FRC root canal post and composite resin crown. It should be noted that leaving $4 \mathrm{~mm}$ of fiber bundle above the root openings in this study might have achieved the ferrule effect, therefore indicating no difference in the failure mode among the preparation types. Earlier study showed that the FRCsubstructure (woven) presented favorable failure modes without significant decrease in the load-bearing capacity [22]. The results of the present study are in agreement with this statement and showed favorable fractures.

The cervical root fractures can be explained by the stress distribution in teeth restored with individually formed FRC root canal post and composite resin crown. As described by earlier investigations, root dentin might have absorbed part of the strain, but on other side, it conveyed limited deformations to the glass post, stress arose at the root interface because of the difference in mechanical resistance between the post and the dentin [36]. The specimens in the present study did not show deformations of the glass post. The fractures could have originate from the adhesive surface between the crown and root and propagated toward the post. This is in accordance with the previous study of Garoushi et al, where root fractures originate from regions with excessive stress concentrations and propagate by exploring the mechanically weak areas in the restoration [22]. The specimens in the present study showed cervical root fracture that propagated toward the post and transferred to the root thereby suggesting good bonding between the post and the root, because of the bigger surface bonding area in the root than in the crown.

Methodologically, one limitation of the present study is related to teeth were placed at the middle of the acrylic cylinders and the fracture occurred only in the teeth and not in the acrylic block. The teeth were held in place with the rigid acrylic resin, which is more akin to an ankylosed tooh. Moreover, the specimens in this study were not thermocycled which has effect of degradation of the luting agent and may possibly influence the results. Anterior teeth contact in a variety of positions and angels, which were not tested in this study. Only one loading point and one angle were tested. Finally, only maxillary canines were used, therefore these results may be only applied to that group of teeth.

\section{CONCLUSION}

Within the limitations of this study, it can be concluded that individually formed fiber-reinforced (FRC) root canal post improved the fracture load of the post-crown system and significantly contributed to the reinforcement and strengthening the restored teeth by supporting the tooth structure. The tooth preparation influenced the fracture load of FRC-crown and $2 \mathrm{~mm}$ uniform ferrule played important role in reinforcing the cervical area where the most fractures occurred. Restorations made from FC revealed similar load bearing capacity than those reinforced with glass-fiber post.
Both, crown design and existence of FRC-post effected significantly fracture types. The fracture pattern with or without post corresponded with the load values, which might suggest that FC plays major role in load bearing capacity.

\section{REFERENCES}

[1] Krasteva K. Clinical application of a fiber-reinforced post system. J Endodont 2001; 27(2): 132-3.

[2] Zhi-Yue L, Yu-Xing Z. Effect of post-core design and ferrule on fracture resistance of endodontically treated maxillary central incisors. J Prosthet Dent 2003; 89: 368-73.

[3] Tan PLB, Aquilino SA, Gratton DG, et al. In vitro fracture resistance of endodontically treated central incisors with varying ferrule heights and configurations. J Prosthet Dent 2005; 93: 331-6.

[4] Pereira JR, Ornelas F, Conti PCR, Valle AL. Effect of a crown ferrule on the fracture resistance of endodontically treated teeth restored with prefabricated posts. J Prosthet Dent 2006; 95: 50-4.

[5] Pontius O, Hutter JW. Survival rate and fracture strength of incisors restored with different post and core systems and endodontically treated incisors without coronoraducular reinforcement. J Endodont 2002; 28(10): 710-5.

[6] Le Bell AM, Tanner J, Lassila LV, Kangasniemi I, Vallittu PK. Depth of light-initiated polymerization of glass fiber-reinforced composite in a simulated root canal. Int J Prosthodont 2003; 16(4): 403-8.

[7] Le Bell AM, Tanner J, Lassila LV, Kangasniemi I, Vallittu P. Bonding of composite resin luting cement to fiber-reinforced composite root canal posts. J Adhes Dentist 2004; 6(4): 319-25.

[8] Hayashi M, Sugeta A, Takahashi Y, Imazato S, Ebisu S. Static and fatigue fracture resistances of pulpless teeth restored with postcores. Dent Mat 2008; 24(9): 1178-86.

[9] Lassila LV, Tanner J, Le Bell AM, Narva K, Vallittu PK. Flexural properties of fiber reinforced root canal posts. Dent Mat 2004; 20(1): 29-36.

[10] Stewardson DA, Shortall AC, Marquis PM, Lumley PJ. The flexural properties of endodontic post materials. Dent Mat 2010; 26(8): 730-6.

[11] Mannocci F, Ferrari M, Watson TF. Intermittent loading of teeth restored using quartz fiber, carbon-quartz fiber, and zirconium dioxide ceramic root canal posts. J Adhes Dent 1999; 1(2): 153-8.

[12] Vallittu PK. In: Curtis R, Watson TF, Eds. Dental Biomaterials: imaging, testing and modelling. Cambridge, CRC Press 2008; 23960.

[13] Bell AM, Lassila LV, Kangasniemi I, Vallittu PK. Bonding of fiber-reinforced composite post to root canal dentin. J Dent 2005; 33(7): 533-9.

[14] Vallittu PK. Interpenetrating polymer networks (IPNs) in dental polymers and composites. J Adhes Sci and Technol 2009; 23: 96172.

[15] Vallittu PK. Fibre-reinforced composites in root canal anchoring. Int Dent South Africa 2006; 8(2): 20-7.

[16] Kalkan M, Usumez A, Ozturk AN, Belli S, Eskitascioglu G. Bond strength between root dentin and three glass-fiber post systems. J Prosthet Dent 2006; 96: 41-6.

[17] Balbosh A, Kern M. Effect of surface treatment on retention of glass-fiber endodontic posts. J Prosthet Dent 2006; 95: 218-23.

[18] Stockton LW. Factors affecting retention of post systems: a literature review. J Prosthet Dent 1999; 81: 380-5.

[19] Aykent F, Kalkan M, Yucel MT, Ozyesil AG. Effect of dentin bonding and ferrule preparation on the fracture strength of crowned teeth restored with dowels and amalgam cores. J Prosthet Dent 2006; 95: 297-301.

[20] Alves de Oliveira J, Pereira JR, Lins do Valle A, Zogheib LV. Fracture resistance of endodontically treated teeth with different heights of crown ferrule restored with prefabricated carbon fiber post and composite resin core by intermittent loading. Oral Surg Oral Med Oral Pathol Oral Radiol Endodontol 2008; 106(5): e52-7.

[21] Akkayan B. An in vitro study evaluating the effect of ferrule length on fracture resistance of endodontically treated teeth restored with fiber-reinforced and zirconia dowel systems. J Prosthet Dent 2004; 92: 155-62.

[22] Garoushi S, Vallittu PK, Lassila LVJ. Direct restoration of severely damaged incisors using short fiber-reinforced compsote resin. J Dent 2007; 35(9): 731-6. 
[23] Garoushi S, Vallittu PK, Lassila LVJ. Fracture resistance of short random oriented glass fiber reinforced composite premolar crowns. Acta Biomat 2007; 3: 779-84.

[24] Garoushi S, Vallittu PK, Lassila LVJ. Continuous and short fiber reinforced composite in root post-core system of severely damaged incisors. Open Dent J 2009; 18; 3: 36-41.

[25] Garoushi S, Vallittu PK, Lassila LVJ. Short glass fiber reinforced restorative composite resin with semi-interpenetrating polymer network matrix. Dent Mat 2007; 23: 1356-62.

[26] Garoushi S, Vallittu PK, Lassila LVJ. Use of isotropic short fiber reinforced composite with semi-interpenterating polymer network matrix in fixed partial dentures. J Dent 2007; 35: 403-8.

[27] Keulemans F, Lassila LV, Garoushi S, Vallittu PK, Kleverlaan CJ, Feilzer AJ. The influence of framework design on the load-bearing capacity of laboratory-made inlay-retained fiber-reinforced composite fixed dental prostheses. J Biomechan 2009; 42: 844-9.

[28] AL-Wahadni AM, Hamdan S, Al-Omiri M, Hammad MM, Hatamleh MM. Fracture resistance of teeth restored with different post systems: in vitro study. Oral Surg Oral Med Oral Pathol Oral Radiol Endodontol 2008; 106: e77-e83.

[29] Sidoli GE, King PA, Setchell DJ. An in vitro evaluation of a carbon fiber-based post and core system. J Prosthet Dent 1997; 78: 5-9.

[30] Le Bell-Rönnlöf AM, Lassila LV, Kangasniemi I, Vallittu P. In: Fiber-reinforced composites as root canal posts. Ph.D. diss., Dept. Of Dentistry, University of Turku 2007; 123-30.
[31] Fokkinga WA, Kreulen CM, Le-Bell A-M, Lassila LVJ, Vallittu PK, Creugers NHJ. In vitro fracture behaviour of maxillary premolars with metal crowns and several post-and-core systems. Eur J Oral Sci 2006; 114: 250-6.

[32] Qing H, Zhu Z, Chao Y, Zhang W. In vitro evaluation of the fracture resistance of anterior endodontically treated teeth restored with glass fiber and zircon posts. J Prosthet Dent 2007; 97: 93-8.

[33] Mendoza DB, Eakle WS, Kahl EA, Ho R. Root reinforcement with a resin-bonded preformed post. J Prosthet Dent 1997; 78: 10-5.

[34] Eraslan O, Aykent F, Yücel T, Akman S. The finite element analysis of the effect of ferrule height on stress distribution at post-andcore-restored all-ceramic anterior crowns. Clin Oral Investigat 2009; 13(2): 223-7.

[35] Torbjörner A, Karlsson S, Syverud M, Hensten-Pettersen A. Carbon fiber reinforced root canal posts. Mechanical and cytotoxic properties. Eur J Oral Sci 1996; 104: 605-11.

[36] Salameh Z, Sorrentino R, Ounsi HF, Sadig W, Atiyeh F, Ferrari M. The effect of different full-coverage crown systems on fracture resistance and failure pattern of endodontically treated maxillary incisors restored with and without glass fiber posts. J Endodont 2008; 34(7): 842-6.

[37] Pierrisnard L, Bohin F, Renault P, Barquins M. Corono-radicular reconstruction of pulpless teeth: a mechanical study using finite element analysis. J Prosthet Dentist 2002; 88: 442-8.

(C) Bijelic et al.; Licensee Bentham Open.

This is an open access article licensed under the terms of the Creative Commons Attribution Non-Commercial License (http://creativecommons.org/licenses/by-nc/3.0/) which permits unrestricted, non-commercial use, distribution and reproduction in any medium, provided the work is properly cited. 